\title{
Diet and Cancer Prevention
}

\author{
Koushiki Mani ${ }^{1}$ Johnny S. Karini ${ }^{1}$ Ananya Amrit ${ }^{2}$ \\ ${ }^{1}$ Department of Medical Review, TCS, Mumbai, Maharashtra, India \\ 2Department of Obstetrics and Gynecology, Sakra World Hospital, \\ Bengaluru, Karnataka, India
}

Ind J Med Paediatr Oncol 2021;42:309-309.

We have read an interesting review article by Venniyoor about the obesity-related cancers in your esteemed journal. ${ }^{1}$ Cancer is the leading cause of death in almost every country and dietary factors are emerging as important risk factors in the development of cancer. ${ }^{2}$ As per the report of World Health Organization/International Agency for Research on Cancer working group on weight control and physical activity, excess body weight is responsible for $\sim 39 \%$ of endometrial, $25 \%$ of kidney, $11 \%$ of colon, and 9 to $11 \%$ of postmenopausal breast cancer. ${ }^{3}$ Meta-analysis of data has shown that for every $100 \mathrm{~g} /$ day increase in red and processed meats, the risk of colon cancer increases by $37 \%$ and the risk of colorectal cancer increases by $29 \%$ for every $100 \mathrm{~g} /$ day increase in red meat and $21 \%$ for every $50 \mathrm{~g} /$ day increase in processed meat. ${ }^{4}$ Alcohol consumption increases the risk of liver and stomach cancer and it is observed that the risk of endometrial cancer is increased by consumption of food with a high glycemic load. Therefore, considerable attention must be given to the composition of diet and healthy lifestyle choices should be followed.

Mediterranean diet is a plant-based dietary pattern containing large amount of complex carbohydrates, fruits, vegetables, beans, and nuts. This diet also includes a moderate amount of dairy products and fish, which limits the intake of red meat and alcohol. Consumption of healthy fat like extra-virgin olive oil, nuts, and fatty fish is the mainstay of a Mediterranean diet. Extra-virgin olive oil contains oleocanthal that has antiinflammatory properties. Fruits rich in antioxidant are an integral part of Mediterranean diet. The polyphenol content of these antioxidants helps to reduce inflammation. Emerging studies have shown that Mediterranean diet is negatively associated with inflammatory markers like C-reactive protein and interleukin-17. Recent researches have shown that dysbiosis is a risk factor for multiple types of cancer. Studies have shown that high-level adherence to Mediterranean diet is positively associated with changes in beneficial gut microbiome. ${ }^{5}$ Studies have shown that adherence to Mediterranean diet may help in the reduction of cancer incidence. ${ }^{6}$ Therefore, we can conclude that the
Address for correspondence Koushiki Mani, MD, TCS, Mumbai, Maharashtra 400607, India (e-mail: koushiki.cmc@gmail.com).

primary prevention of cancer should emphasize on incorporation of healthy diet and modification of various lifestyle factors.

\section{Take-Home Message}

1. Adopting healthy lifestyle choices like physical activity and avoidance of alcohol reduce cancer risk.

2. Consumption of processed meat and red meat should be strictly avoided as they increase the risk of colorectal cancer

3. Changing the diet to Mediterranean diet modulates the gut microbiota that promotes healthy living.

\section{Funding \\ None.}

\section{Conflict of Interest}

None.

\section{References}

1 Venniyoor A. Obesity-related Cancers: The Coming Epidemic. Indian Journal of Medical and Paediatric Oncology. 2020; 41(3).

2 World Cancer Research Fund \& American Institute for Cancer Research, Diet, Nutrition, Physical Activity and Cancer: A Global Perspective. WCRF International; 2018

3 International Agency for Research on Cancer, IARC Handbooks of Cancer Prevention. Vol 6. Weight Control and Physical Activity. Lyon: IARC; 2002

4 Chan DSM, Lau R, Aune D, et al. Red and processed meat and colorectal cancer incidence: meta-analysis of prospective studies. PLoS One 2011;6(6):e20456

5 Ghosh TS, Rampelli S, Jeffery IB, et al. Mediterranean diet intervention alters the gut microbiome in older people reducing frailty and improving health status: the NU-AGE 1-year dietary intervention across five European countries. Gut 2020;69(7):1218-1228

6 Fliss-Isakov N, Kariv R, Webb M, Ivancovsky D, Margalit D, Zelber-Sagi S. Mediterranean dietary components are inversely associated with advanced colorectal polyps: a case-control study. World J Gastroenterol 2018;24(24):2617-2627
DOI https://doi.org/ $10.1055 / \mathrm{s}-0041-1732813$ ISSN 0971-5851 (c) 2021. Indian Society of Medical and Paediatric Oncology.

This is an open access article published by Thieme under the terms of the Creative Commons Attribution-NonDerivative-NonCommercial-License, permitting copying and reproduction so long as the original work is given appropriate credit. Contents may not be used for commercial purposes, or adapted, remixed, transformed or built upon. (https://creativecommons.org/licenses/by-nc-nd/4.0/).

Thieme Medical and Scientific Publishers Private Ltd. A-12, Second Floor, Sector -2, NOIDA -201301, India 